Peer-Reviewed Article

ISSN: 2162-3104 Print/ ISSN: 2166-3750 Online

Volume 5, Issue 3 (2015), pp. 285-299

(C) Journal of International Students

http://jistudents.org/

\title{
A Phenomenological Study on International Doctoral Students' Acculturation Experiences at a U.S. University
}

\author{
Throy A. Campbell (Doctoral Candidate) \\ University of Texas at Arlington (USA)
}

\begin{abstract}
A phenomenological method was used to analyze ten international doctoral students' description of their lived experiences at a United States (U.S.) university. The analysis was based on the theoretical premise of how students acculturate to their new educational settings. Three broad overlapping themes emerged: (1) participants' past experiences that influenced their desire to study in the U.S.; (2) participants' interactions within academic and non-academic settings; and (3) the role of family relationships during their studies within the U.S. The study revealed that the students: were optimistic about the societal opportunities from studying in the U.S., were appreciative of their interaction with instructors, had inadequate relationship with supervising professors, participated in limited social activity outside of academic settings, and made adjustment to family relationships.
\end{abstract}

Keywords: International Doctoral Students, Acculturation, Higher Education, United States

The increasing presence of international graduate students at American universities is making these higher education institutions more culturally diverse. In the academic year 2012-13, about 311, 204 international graduate students enrolled at U.S. universities, an increase of $3.4 \%$ from the previous year of 2011-12 (Institute of International Education, 2013). These students were from Asia (69.4\%), Europe (9.4\%), Middle East and North Africa (7.9\%), Latin America and the Caribbean (6.4\%), North America (3.5\%), and Sub-Saharan Africa and Oceania (3.4\%). About 117,779 international graduate students were enrolled in doctoral programs, which represented a 13\% increase since the academic year 2004-05(Institute of International Education, 2013). This diverse student group brings global perspectives and knowledge background, particularly in science fields to United States' (U.S.) doctoral programs (Knox et al., 2013; Sato \& Hodge, 2009). In addition, they contribute to America's economic strength through scholarly research, patenting, and creation of knowledge-based products and services (Chellaraj \& Maskus, 2008; National Science Board, 2014).

Although international students enrich American doctoral programs, previous studies show that they face certain acculturation challenges that affect their social wellbeing and academic success. Acculturation challenges refer to the cultural and psychological adjustments that an individual or cultural group endures within a new environment (Berry, Phinney, Sam, \& 
Vedder 2006). International students at all degree levels encounter unfamiliar teaching practices, communication barriers, and identity issues (Jackson, Ray, \& Bybell, 2013; Kim, 2012; Kuo, 2011; Sherry, Thomas, \& Chui, 2010; Young, 2011; Sue \& Rawlings, 2013; Telbis, Helgeson, \& Kingsbury, 2014). Furthermore, studies on doctoral students highlight: cultural insensitivity by academic advisors and research supervisors (Sato \&Hodge, 2009); indifferent mentoring relationships, and inadequate career guidance (Knox et al., 2013).

Given the contributions that international doctoral students make to America's higher education institutions (scholarly research) and economy (knowledge-based products and services), this paper provides further understanding of doctoral students' experiences at a particular U.S. university.

\section{Literature Review}

\section{Experiences of Undergraduate and Master's Students}

Undergraduate and master's degree students at U.S. colleges report various cultural and social issues. These include differences with the norms and social practices of American society (Jackson, Ray, \& Bybell, 2013; McLachlan \& Justice, 2009; Sherry, Thomas \& Chui, 2010); identity complications due to race and ethnicity (Kim, 2012); and disruptions of family relationships due to academic demands and distance from home (Poyrazli \& Kavanaugh, 2006; Zhang, Smith, Swisher, Fu, \& Forgarty, 2011). These issues are common to both domestic and international students who travel away from home to different college locations. However, there are certain significant challenges that directly affect the international student population, particularly, the lack of English language proficiency and adjustments to differences in teaching approaches (Kim, 2011; Kuo, 2011; Sherry, Thomas, \& Chui, 2010; Telbis, Helgeson, \& Kingsbury, 2014). Within the American academic culture, students contribute to each other's learning experiences through group discussions and projects. This level of interaction among students is difficult during the early stages of the international students' tenure as they are of diverse educational backgrounds with different teaching methods and student values (Kim, 2011; Young, 2011). Furthermore, those who speak English as a second language have difficulties interrelating with peers and instructors, and feel challenged by the expectations of academic writing and oral presentations (Kim, 2012; Sue \& Rawlings, 2013).

Similar troubles were evident outside of classroom settings as foreign students try to

integrate with the American community (Chavajay, 2013). Burkholder's (2013) phenomenological study on the lived experiences of six full-time, single Turkish graduate students reveals that it is difficult for them to associate with individuals of different cultural backgrounds. The participants report that language barriers, cultural differences, and academic demands hinder their adaptation to the American way of life.

\section{Experiences of Doctoral Students}

English language barriers and differences with societal practices were also common to international doctoral students at U.S. universities. However, they encounter problems unique to their experiences. Sato and Hodge's (2009) case-study on 18 Asian doctoral students in various fields of studies, and Le and Gardner's (2010) research on nine Asian international doctoral students in the science, technology, engineering, and mathematics (STEM) areas reveal various difficulties they experience as graduate researchers and teaching assistants (GTA/GRA). As nonimmigrants with restricted work authorization, they depend on these positions as a source of 
monthly income, for tuition scholarships, and opportunities to build their research credentials. However, these positions are normally funded by professors' research budgets (Le \& Gardner, 2010; Sato \& Hodge, 2009). As a result, the students feel obligated and are overwhelmed to maintain quality relationships with their research supervisors.

The importance of the student advisor relationship was also researched by Knox et al. (2013). The focus was Asian doctoral students within a U.S. based counseling psychology doctoral program. Some participants report that they expect emotional and social support on how to handle the demands of their degree programs and to prepare for their future careers, but find such support not forthcoming. Nevertheless, there were also positive findings in the study; advisors who had previous experience with international students were professional and supportive.

The purpose of this study is to provide an understanding of international doctoral students' acculturation experiences at a particular U.S. university. This university is recognized for its growing population of international students with a variety of cultural and linguistic backgrounds (Institute of International Education, 2013).

\section{Research Questions}

The following research questions will be addressed:

1) What previous educational and life experiences influence the students' decision to study and their ability to acculturate at U.S. universities?

2) What previous educational and life experiences influence the students' ability to acculturate at U.S. universities?

3) How do international doctoral students perceive their relationships with members of the U.S. academic community inside and outside of academic settings?

4) How do international doctoral students' family relationships and responsibilities affect their acculturation experiences?

\section{Conceptual Framework}

This study is guided by the theory of acculturation, which refers to the cultural and psychological changes that individuals and groups undergo when in prolonged contact with people of another culture (Redfield, Linton, \& Herskovits, 1936). Cultural changes refer to migrants (immigrants) adaptation to the societal practices and norms of the host, whereas psychological changes refer to one's mental receptiveness towards the new culture and willingness to identity with others (Berry, Phinney, Sam, \& Vedder, 2006). Upon entering a new environment, individuals experience behavioral changes and acculturative stress. Eventually, over the long-term individuals identify with others who share similar encounters as they choose to assimilate, separate, integrate, or marginalize. Berry (2003) defines these approaches to acculturation as follows: 1) assimilation, which is when the individual is willing to be a part of another culture 2) separation, is when the individual holds on to their original culture and do not wish to be a part of another; 3) integration, is when the individual has an interest in a second culture but wants to hold on to their own simultaneously; and finally, 4) marginalization, is when there is little chance of maintaining one's original culture and little interest to be a part of a new culture.

This acculturation experience is primarily dependent on whether participants freely choose to acculturate or not. However, in a situation where the dominant forces its culture, more critical strategies are appropriate (Chun, Organista, \& Marin, 2002). Furthermore, Padilla, and 
Perez (2003) put forward a model that suggest ones' social cognition helps individuals to adapt to a new culture without losing ones' original beliefs or values.

The acculturation framework has been used to examine various migrant experiences. These inquiries focus on experiences of ethnic populations (Chun, Organista, \& Marin, 2003); influences on cultural values (Marin, Gamba, Chun, \& Organista, 2003); processes on the family (Santisteban, Mitrani, Chun, Organista, \& Marin, 2003); and learning experiences of students (Vedder \& Horenczyk, 2006). The current study uses the latter, which conceptualizes acculturation within school settings. This approach has been used to frame the immigrant students' socialization as they go through the process of learning behaviors, knowledge, and values of the host culture. As Vedder and Horenczyk (2006) described, immigrant students develop acculturation patterns as they go through the acculturation process. These patterns may vary depending on perceptions of the level of differences between the home and host culture. The differences may be linked to individual (e.g., academic skills, nationality, and selfmotivation) and institutional factors (e.g., field of study, university policies, and teaching methods).

Furthermore, acculturation patterns in schools are dependent on one's ability to become academically competent, to develop independence, and to create social relationships (Greenfield, Keller, \& Maynard, 2003). Students who show competence are able to learn new skills and knowledge, have the confidence to participate in class interactions and projects Vedder \& Horenczyk, 2006), and are proficient in the language of the host country (Alkan, 1998). The students who demonstrate independence have a personal drive to overcome obstacles and to explore new research areas and build collegial networks (Polfreyman, 2003). Those networks include relationships with peers who represent a source of companionship and social support (Newcomb \& Bangwell, 1995).

The current study extends the application of the theory to international doctoral students in the university environment. These students are classified as non-immigrants, as they were all on temporary student visas to the U.S. The premise of the acculturation theory provides a helpful framework to explore the factors that influence international doctoral students' adaptability to the U.S. academic culture and ability to maintain (or not) relationships with members of the American society.

\section{Research Method}

This study has a phenomenological design with qualitative methods of inquiry (Crotty, 1998; Maxwell, 2013). Phenomenology allows the researcher to focus on "the subjectivity of reality... on how humans view themselves and the world around them" (Willis, 2007, p. 53). This enables in-depth understanding of the students' perspectives of the same phenomenon by keeping the researchers' prejudices at a minimum so as to allow the purity participants' perspectives to emerge (Fischer, 2009).

\section{Validity}

There are various constructive critiques of phenomenological methods of inquiry. First, participants may interpret interview questions differently, particularly international students of different linguistic backgrounds. As a result, the researcher clearly identified the phenomenon and then elicited the participants' descriptions of their personal experiences (Creswell, 2013). The accumulative descriptions allowed the researcher to identify similar themes within the 
different perspectives. Second, the researcher's subjectivity during the analysis process can also affect the validity of the investigation. As a result, bracketing techniques were used to exclude the researcher's presuppositions (Maxwell, 2013). The following steps were taken: during data collection process the researcher wrote memos as a form of reflection on how involved one gets into the interview process (Creswell, 2013). A key point of reflection was whether the participant was allowed to freely express their feelings without the imposition of the researcher's insights. The researcher also kept a reflexive journal of hunches on the participants' descriptions. By identifying these presuppositions upfront (i.e. agreements and disagreements) the researcher was able to include only the participants' descriptions in emerging themes (Ahern, 1999; Creswell, 2013).

\section{Research Site and Participant Selection}

The U.S. university in the South that was the site for this study was chosen due to its high enrolment of doctoral students from different countries. The aim was to interview a number of participants that were as representative as possible of the international student population at the university. Nonetheless, the only screening criterion was that participants had to be enrolled as international (non-immigrant) doctoral students. Consent was obtained from the university institutional review board (IRB), and the same office also provided email addresses of all international doctoral students enrolled at the university. All students were emailed and invited to participate, of which 10 consented and were interviewed.

\section{TABLE 1}

\section{Demographic Characteristics of Participants}

\begin{tabular}{lllllll}
\hline Pseudonym & Department & Nationality & Sex & Age (yrs.) & $\begin{array}{l}\text { Marital } \\
\text { Status }\end{array}$ & $\begin{array}{l}\text { Months in } \\
\text { the U.S. }\end{array}$ \\
\hline Ade & SUPA & Indonesia & Female & 35 & M & 70 \\
Bibek & Marketing & Indian & Male & 24 & S & 24 \\
Darika & Engineering & Nepal & Female & 30 & S & 70 \\
Fifi & SUPA & Ghanaian & Male & 30 & S & 36 \\
Fu & Math & Chinese & Male & 28 & M & 22 \\
Rasa & SUPA & Iranian & Female & 33 & M & 24 \\
Saanvi & Engineering & Indian & Male & 41 & M & 84 \\
Salman & Marketing & Saudi & Male & 29 & M & 84 \\
Sholeh & Accounting & Indian & Female & 31 & M & 150 \\
Zhen & Engineering & Chinese & Female & 24 & S & 24 \\
\hline
\end{tabular}

SUPA - School of Urban and Public Affairs

The diversity of the participants allowed the researcher to gain the essence of the international doctoral students' experience in the context of which it occurred (Creswell, 2013), considering the diversity of the university population and the different field of studies offered. Demographic information of the participants is presented in Table 1. In the context of the acculturation theoretical framework used in this study, it is important to note that the participants were between the ages of 24 and 41, and they all had spent at least 24 months within the U.S. However, the time spent was not necessarily as a doctoral student, but they may have been enrolled previously in graduate and undergraduate programs 


\section{Data Collection}

A demographic questionnaire and a semi-structured interview protocol were used for data collection. The protocol was based on pre-existing literature on international students at U.S. colleges and the acculturation propositions within a school setting (Berry, et al., 2006; Vedder \& Horenczyk, 2006). In-person interviews were conducted, and clarifications were obtained via email from the participants (Creswell, 2013; Fontana \& Prokos, 2007). Interviews were conducted by the principal researcher at a site convenient to each participant. The interviews had two segments. The first focused on the participants' previous higher education experiences in their home country and the second segment focused on the students' experience during their doctoral studies in the U.S. The semi-structured interviews allowed the researcher to probe for detail descriptions, and the open-ended questions allowed participants to reflect and speak about their social and academic experiences.

\section{Data Analysis}

The first step was to write an observation memo within 12 hours after each interview. This provided an opportunity to document the interview experience of each participant (Emerson, Fertz, \& Shaw, 2011). The second step was to listen to tape recordings without transcribing, and made further notes on what was heard in the data. Tentative ideas on contextual relationships and broad themes were noted (Emerson, Fertz, \& Shaw, 2011; Maxwell, 2013).

The third step was multifaceted, which involved verbatim transcription of audio recordings, followed by coding of data into organizational, substantive, and theoretical categories (Maxwell, 2013; McMillan \& Schumacher, 2001). The transcripts along with interviewer's memos and journal notes were read repeatedly (at least thrice) to identify categories. The organizational categories were primarily sorted data based on descriptive topics that were within the scope of research questions (i.e., previous educational experience, reasons for studying in the U.S., experiences with professors, and experiences with peers). The substantive categories are non-theoretical but were based on the participants' perceptions and beliefs about their experiences. The theoretical categories included coded data based on acculturation concepts. This involved the matching of participants' perspectives with theoretical propositions. The overall process was iterative, and involved methodological triangulation through cross checking audio recordings, demographic questionnaires, and reflection memos. This multifaceted coding process enabled the researcher to identify relationships that connect statements into a coherent whole, while retaining the purity of the descriptions.

Additional steps were taken to ensure accuracy of the data analysis. A qualitative researcher was allowed to cross-checked the emerging themes from anonymous interview transcripts, researcher reflection memos, and conceptual maps. Furthermore, member checking was done, as the broad themes were emailed to the participants for their critique on the representativeness of the data.

\section{Analysis and Discussion}

Three broad overlapping themes emerged from the analysis of the students' descriptions of their experiences: (1) previous experiences that influenced their willingness to study in the U.S.; (2) interactions within academic and non-academic settings; and (3) the role of family relationships during their studies. As noted previously in the discussion section, it may be of importance to 
note that all participants have spent at least 24 months within the U.S. at the time of their interviews. This length of stay may have impacted their perspectives.

\section{Reasons for Studying in the U.S.}

The students provided academic and societal reasons that influenced their decisions to pursue higher education studies abroad, which enabled the researcher to identify initial factors that influenced how they acculturated to their new academic environment (Berry, Phinney, Sam, \& Vedder, 2006; Jackson, Ray, \& Bybell, 2013; Vedder \& Horenczyk, 2006). For example, Rasa, an Iranian, noted that: "U.S. doctoral programs are regarded as the best, which is evident in academic journals". This admiration for the U.S. doctoral academic programs show that the students' investigated the quality of doctoral programs offered by institutions in different countries, and made decisions based on the type of empirical research published in academic journals. In addition, the students also expressed that a doctorate from a U.S. institution would give them an advantage in the global labor market.

Furthermore, the students were critical of the teaching styles used by professors in their home countries. According to Ade, an Indonesian: "My instructors were not all interactive; they were seen as exacting experts.... I looked at my professor as someone who knew it all; I believed their approach were not accommodating for doctoral level research". Also, Salman, a Saudi, mentioned: "My professors spent little time teaching and do not involve students. In addition, they had little resources to conduct quality research".

There were also societal reasons why the students chose to study in the U.S. A noteworthy perspective was that of the Iranian student. Rasa's comments were representative of the others: "Considering the unsettled political environment of my country, the option to study in the U.S. provides an opportunity to reside and start life anew". The female participants also expressed socially related perspectives. For instance, according to Darkita a Nepali: "My mother and grandmother invested in my doctoral studies, as she saw it as an escape from societal expectations for females to get married at an early age".

The participants' comments did not clearly outline the level of difference between the students' native and American education systems; however, their optimistic outlook of the American university and societal opportunities likely played a positive role in the students' acculturation. For example, studies have shown that positive perceptions of host culture and practices make adjustments smoother (Heath, 1983; Zentella, 1997). Previous studies outline transitional issues that international students faced (Jackson, Ray, \& Bybell, 2013; E. Kim, 2012; H. Kim, 2011), but an understanding of their motivation for studying in the U.S, provides a perspective on their willingness to acculturate. The Iranian described that studying in the U.S. provides opportunities to reside or start life anew. This is an area for further enquiry on whether students see their doctoral studies as a "break" from home culture, or plan to reside long-term. This may influence their willingness to assimilate or be a part of another culture.

\section{Interactions within Academic and Non-academic Settings}

According to Vedder and Horenczyk (2006), immigrant students eventually acculturate to their new school environments by learning new skills and knowledge, and accepting of values transmitted by the host culture. This proposition was evident in the international doctoral students' descriptions of their experiences with members of the university community within academic and non-academic settings. The descriptions and analysis were organized in the 
following themes: interactions with instructors, exchanges with classmates, experiences with supervising professors, and interactions outside academic settings.

Interactions with instructors. The participants had varied perspectives but were appreciative of their interactions with their instructors. They emphasized the different approaches used by American instructors. Salman's description was typical of the others: "It was a lot of lectures in the beginning, but I liked that. In some classes, the professor encouraged discussion". However, some students expressed frustration. Sholeh, a Nepalese student, mentioned that the level of classroom interaction expected from students was a challenge for her: "As a female, I was never encouraged to talk in Nepal not even in family settings, here it was the exact opposite, instructors expect you to contribute to class discussions, and I had a very hard time". Nevertheless, some participants appreciated that professors helped them acculturate. For example, according to Darika, "my professor had a lot of experience with international students and he understood my cultural and social difficulties".

The above descriptions show varied signs of acculturation as outlined in Vedder and Horenczyk's work on acculturation in school settings (2006). The participants showed willingness to adapt to the teaching methods of the university instructors; however, difficulty in speaking openly in class discussions was a challenge for some students and may have reduced classroom interaction and participation. This difficulty was documented in previous studies on Asian students. It was revealed that within the American classroom students are expected to contribute to each other experience. As a result, students who spoke English as a second language (Kim, 2011) and those who were from cultures that had a passive approach to speaking openly (Zhai, 2002), experienced acculturation barriers. These teaching approaches employed in the American classroom are somewhat forceful, as the international student has little chance but to adapt, even though some instructors were more understanding than others. It is possible that the strategy of assimilation was used by the students as they have academic interest and was willing to learn how to communicate proficiently.

Interactions with classmates. Developing social relationships with peers was posited as a contributing factor towards immigrants' acculturation experience in the academic setting (Newcomb \& Bangwell, 1995). This was evident in the students' experience as they assimilated and developed relationships with peers that provided opportunities to practice social and language skills.

Participants reported that their classes were diverse. Salman noted: "In my cohort there were five internationals [of] ... different countries, which caused us to get along since we shared similar struggles". At the same time, Sholeh made positive comments about her American classmates: "my best friends were Americans; they were very caring... They helped me adapt to the professors teaching methods and helped me talk up in class". Sholeh also emphasized the need to work together as doctoral students:

I do not think it matters which culture you are from, there are certain handicaps we all have. My Chinese friends are strong quantitatively while I might have the advantage of understanding English better. I think even with all of these differences focusing on your strengths will help you succeed.

Here, the international students showed social aptitude toward acculturation; they employed the assimilation strategy and adapted to the multi-cultural nature of the doctoral program by developing relationships with both American and domestic students. 
Nonetheless, the participants also expressed that the nature of doctoral programs required considerable independent work. For example, Darika mentioned: "In my doctoral studies it is difficult to collaborate as I need to do a lot of personal research".

Interactions with supervising professors. This study also demonstrates how doctoral students' interaction with their supervising professors affected their acculturation patterns. Nine of the participants worked as Research and Teaching Assistants with professors in their respective academic department. This working relationship was critical to the student's academic success because the professors also provided mentoring support.

Darika gave two perspectives of the types of experiences international doctoral students have with their research supervisors. She had to change from one supervisor to another due to relationship difficulties. As an international GRA she depended on benefits from the job, such as reduced tuition and a monthly stipend. She exclaimed: "I was taken advantage of! Most, because ...your work is not always appreciated ... [this] dampens the quality of your life. Doctoral students expect to be respected, but my professor was not professional". The problem worsened because Darika had hoped to work with this particular professor for her dissertation study. As a result, she changed research interest, which extended her time as a doctoral student. Nevertheless, her second supervisor understood her life situation. She noted: "in the case of supervising professor under whom I successfully completed my dissertation, her expectations were clear. She understood your needs as a female student, which I do not think male professors exactly understand or encourage". Darika comments provide a view on the differences in experiences of female students with professors and supervisors of the opposite sex. This is an area for further research. However, earlier studies on undergraduate and graduate international students' at U.S. universities show that females' acculturation were negatively affected due to their view of traditional gender role and expectations in society (Lee, Park, \& Kim, 2009; Marville, 1981), even though there were differences based on country of origin (Min, 2001; Tang \& Dion, 1999; Ying, 2002). On the other hand, empirical evidences show that gender related issues can be motivational for females who are exposed to western cultures. These students endeavor to achieve a higher social status (Kindlon, 2006; Ying \& Han, 2006).

Another issue was the participants' willingness to show initiative and to communicate with their supervisors. Zhen, a Chinese, described her interactions, which were typical of other Asian female participants': "I am not a very open person ... I only talk to him whenever I have some progress with my research.... I did not become a very close friend with my supervisor". On the other hand, the male students had a different perspective. Sasanka noted:

I have seen many students who think that their professors do not help them, and that is why they build that barrier.... You should show good dedication in the beginning, and polish your research. They will see your enthusiasm and be willing to work with you. I think this thing is lacking among some students.

These descriptions of less than desirable interactions with supervising professors affirm the findings of earlier research (Knox et al., 2013; Sato \& Hodge, 2009; (Zhang, Smith, Swisher, $\mathrm{Fu}, \&$ Forgarty, 2011). However, the negative perceptions, and communication challenges the participants of this study had of their supervising professors shows that one's sex and level of personal confidence may influence the type of relationships (Zhang, Smith, Swisher, Fu, \& 
Forgarty, 2011). Difficulty in forming mutual interactions with supervising professors may create cultural and psychological barriers that eventually affect the students' academic work.

Socializing in non-academic settings. The participants had limited involvement in activities outside of academic settings. These interactions provided opportunities to socialize with the American culture and developed a sense of belonging. Seven of the ten participants reported that they were not able to maximize these benefits. For example, Reran mentioned:

I am always in the lab, even during public holidays. Most of my experiments were time sensitive my professor needed results. I have very little social life. I am 28 years old, have no wife or girlfriend, and I am not given the chance to interact with the American society. I love the research but hate the long hours.

Involvement in student organizations was another avenue to socialize with people outside of the classroom setting. Some students were aware of these organizations on campus, which included cultural, religious, and academic groups. They indicated that these organizations enabled them to get involved in campus life and intermingle with compatriots who shared similar on-campus experiences. Some of the participants thought these organizations provided valuable support for international students. For example, Ade was instrumental in forming a PhD student group: "there was a need to create a space for us to talk about our research for conferences".

The majority of the participants were slow to integrate with American society for various reasons. The university campus had a large Asian student population, and as a result, they were able to get together as countrymen. This provided a sense of community but at the same time they became isolated from Americans and other internationals. Bibek, an Indian, thought this was a significant problem: "this ought to be a part of coming to America, where you are able to integrate with a diversity of people and learn from the American society. Some internationals are not even aware of the local news". Rasa, an Iranian had a different perspective on why women from her country found it difficult to integrate: "I feel different treatment from the Americans .... I look different, I dress different, and people are uncomfortable in talking to me. They never call me by my first name which is a common practice by Americans".

The doctoral students also reported that they were slow to integrate with members of the host culture, which may have affected their sense of belonging. Most students stated that due to academic rigor and time constraints they were unable to integrate with other cultural groups. However, others saw the benefits of integrating; they were able to work together and participate in on-campus social activities. In addition, as in previous studies on international students at the undergraduate and masters' levels, the doctoral students preferred to bond with compatriots as they were able to relate to each other (Kim, 2012; McLachlan \& Justice, 2009; Sherry, Thomas, \& Chui, 2010).

\section{The Role of Family Relationships}

This study has highlighted acculturation issues that international doctoral students experienced with their families. Six of the participants were married; their spouses and immediate family members lived with them in the U.S. Two students indicated that their fiancée resided back in their home countries. The other two students were single and reported that their immediate family members lived in other countries or other states in the U.S. There was 
evidence of different family values, but these relationships played significant roles in the students' academic life.

The students who were single expressed that they often felt homesick due to the distance from family, lack of home cooked meals, and being unable to participate in spiritual and cultural events. Darika's experience encompassed the other single students' sentiments: "Well, it was very difficult to speak to family members about my struggles...; my parents can only give spiritual support. They do not understand ... they have not been in academia".

The married students had different experiences; their lives were hectic. Ade, Rasa, and Sholeh's accounts provide a description of the dynamics of family and school life experienced by married doctoral students. Ade gets appreciative support from her husband: "He does not have a $\mathrm{PhD}$, but he actually supports me getting one. Other than family, school is my priority, but I've never had to decide which one I have to go for. I had my son after a year of my program.... I took two weeks off from class and then return".

Rasa and her husband who was also a doctoral student lived with their two kids in an offcampus apartment. She expressed how different issues impacted their relationships: "We had little time, and it was difficult to prepare decent meals. We are not fully funded and are dependent on money from Iran and my graduate work. Because of work and school, he understands if I do not have the time to do domestic work".

Sholeh also described how academic demands affected her family relationships:

I have been focusing on my dissertation and am ready...to ...live a normal life, but when you are in the dissertation phase you do not really have a normal life. In October, we have this huge festival which is part of Nepal's culture. I have cousins in another state, and I would like to go there and celebrate, but I feel this year I will not be able to.

These insights on international doctoral students' family relationships extend the application of the acculturation theoretical framework to understand the role of family relationships within academic settings (Vedder \& Horenczyk, 2006). The single students thought the rigors of academic work prevented certain relationships, but they looked forward to starting families after completing their studies. The married students expressed positive support received from their spouses. There were reports of spouses switching roles, where the student was able to focus on school and also earned an income through research work. The participants' emphasis of their husbands' willingness to take a lead on domestic duties are signs of cultural adjustments.

\section{Limitations of the Study}

There were various limitations to this study. First, it is important to consider the practicality of the participants' ability to articulate their perceptions. The fact that some of the participants were second language English speakers may have affected the richness of information shared (Maxwell, 2012). Also, because of the focus on the participants' descriptions, other factors that are associated or lead up to the experience may have been overlooked.

The participants were selected from one doctoral granting institution. As a result, findings are applicable but not necessarily generalizable to other university settings. Higher education policies and practices differ per university system and by the state in which the institution are located. These institutional differences impacted individual students' experiences. 
The students' experiences may also be examined from a developmental perspective. The typical doctoral program is structured in stages: course-work, teaching opportunities, and dissertation. Also, it would be informative to understand whether the international students think their perspectives were different from American peers. This approach may provide information that can guide administrators and policy makers on reducing attrition factors.

Several of the participants, particularly females provided sexualized and gendered perspectives on their interactions with members of the host culture. However, this study did not provide the space for an extended analysis or the application of a more pertinent theoretical framework. There are clear areas for further research on the experiences of female doctoral students.

In addition, the students provided limited descriptions on how their academic and societal background influences their decision to study at a U.S. university. This is another area for further probing on the choice of U.S. in comparison to other countries.

There were also findings that indicate students may have long term plans of residing in the U.S. due to issues with home country. The acculturation framework can be used to examine if the intent of residing post-graduation affects students' willingness to integrate in host culture. Finally, future studies may incorporate the views of professors, academic advisors/mentors, international advisors, health providers, and domestic students to provide a more comprehensive analysis.

\section{Implications and Conclusion}

Doctoral granting institutions in the U.S enroll the greater share of international doctoral students from around the world (Institute of International Education, 2013). However, global enrollment trends suggest that other countries are now viable options (Institute of International Education, 2013). This investigation has provided an analysis of foreign doctoral students' acculturation experiences at one U.S. doctoral granting institution and obtained findings that have implications for both practitioners and future research. It is important to note that the study has highlighted findings that are common to both international and domestic doctoral students. This implies that efforts by policymakers and education administrators to serve international students will also directly help American students.

This research contributes to the literature with descriptions of how students' educational and cultural backgrounds influence their decision to study in the U.S., and how it affected acculturation to their new environments. Higher educational administrators and policy makers should invest in resources that will enhance the students' acculturation experiences. There are implications for admissions processes, orientation programs, and academic departments.

There is a need for all stakeholders to be culturally responsive. In the context of doctoral programs, academic departments should encourage means by which faculty members and supervising professors can learn of students' cultural differences. This may include collaborating with international admission offices in efforts to learn of the students' background, encourage integration of diverse teaching materials that are familiar to students, and facilitate the formation of mentoring relationships where students are able to relate with supervisors on an individual basis. This one-on-one interaction will allow the discussion of differences and ways to improve working relationships. Mentors are also able to guide students on academic culture, research opportunities, and career options within the U.S. In addition, orientation sessions may also be 
used to inform students of the demands of doctoral studies and provide an environment for interactions with advance students that can share their experiences.

This study also highlights students' descriptions of family relationships on the challenges they encounter and how they adjust to academic and work demands. Due to the fact that doctoral students are mature, as indicated by the participants' age (24 to 41), they are normally involved in family relationships. International admission office may further facilitate the students' acculturation through organizing social family events. Within this setting an American family may adapt an international student and introduce them to the American culture and different resources within the community. University administrators may also provide family housing. This will allow families to share a friendly environment.

There is need for much more empirical studies on international students, particularly at the doctoral level. Understanding the factors that influence the students' acculturation experiences is necessary to make informed decisions on ways to better serve and attract highly qualified individuals to U.S. universities. The international diversification of U.S. doctoral student population will add to the growth of knowledge and innovativeness within university research centers and laboratories.

\section{REFERENCES}

Ahern, K. J. (1999). Pearls, pith, and provocation: Ten tips for reflexive bracketing, Qualitative Health Research, 9(3), 407-11.

Alkan, M. (1998). Ethnicity and underachievement in the Netherlands: A curricular analysis. In C. Wulf, C. (ed.), Education for the $21^{\text {st }}$ Century (pp. 195-212). Munster, Germany.

Berry, J. (2003). Conceptual approaches to acculturation. In K. M. Chun, \& G. Marin (Ed), Acculturation: Advances in theory, measurement, and applied research (17-37). Washington, DC: American Psychological Association.

Berry, J. W., Phinney, J. S., Sam, D. L., \& Vedder, P. (2006). Immigrant youth in cultural transition: Acculturation, identity, and adaptation across national contexts. Mahwah, N.J: Lawrence Erlbaum.

Burkholder, J. R. (2013). Reflections of Turkish international graduate students: Studies on life at a U.S. Midwestern university. International Journal for the Advancement of Counselling, 36(1), 43-57.

Chavajay, P. (2013). Perceived social support among international students at a U.S. university. Psychological Reports: Sociocultural Issues in Psychology, 112(2), 667 - 677.

Chellaraj, G., \& Maskus, K. E. (2008). The contribution of international graduate students to US innovation. Review of International Economics, 16(3), 444-462.

Chun, K., Organista, P., \& Marin, G. (2003). Ethnic identity and acculturation. In K. Chun, P. Organista, \& G. Marin (Eds.), Acculturation: Advances in theory, measurement, and applied research (63-81). Washington, DC: American Psychological Association.

Creswell, J.W. (2013). Qualitative inquiry and research design: Choosing among five approaches (3rd ed.). Thousand Oaks, CA: Sage.

Emerson, R. M., Fertz, R.I., \& Shaw, L.L. (2011) Writing ethnographic fieldnotes. Chicago, IL: University of Chicago Press.

Fischer, C. T. (2009). Bracketing in qualitative research: Conceptual and practical matters. Psychotherapy Research, 19(4-5), 583-590.

Fontana, A., \& Prokos, A. (2007). The interview: From formal to postmodern. Walnut Creek, 
CA: Left Coast Press.

Greemfield, P.M., Keller, H., Fuligni, A., \& Maynard, A. (2003). Cultural pathways through universal development. Annual Review of Psychology, 36(4), 461-490.

Heath, S. B. (1983). Ways with words: Language, life and work in communities and classrooms. New York, NY: Cambridge University Press.

Institute of International Education. (2013). Open Doors, 2013: Report on International Educational Exchange. Retrieved from Publications/Open-Doors/Data

Jackson, M., Ray, S., \& Bybell, D. (2013). International Students in the U.S.: Social and psychological adjustment. Journal of International Students, 3(1), 17-28.

Kim, E. (2012). An alternative theoretical model: Examining psychological identity development of international students in the United States. College Student Journal, 46(1), 99-113.

Kim, H. Y. (2011). International graduate students' difficulties: Graduate classes as a community of practices. Teaching in Higher Education, 16(3), 281-292.

Kindlon, D. (2006). Alpha girls: Understanding the new American girl and how she is changing the world. New York: Rodale.

Knox, S., Sokol, J. T., Inman, A. G., Schlosser, L. Z., Nilsson, J., \& Wang, Y. (2013). International advisees' perspectives on the advising relationship in counseling psychology doctoral programs. International Perspectives in Psychology: Research, Practice, Consultation, 2(1), 45-61.

Kuo, Y. H. (2011). Language challenges faced by international graduate students in the United States. Journal of International Students, 1(2), 38-42.

Le, T., \& Gardner, S. K. (2010). Understanding the doctoral experience of Asian international students in the science, technology, engineering, and mathematics. Journal of College Student Development, 51(3), 252.

Lee, S., Park, H., \& Kim, W. (2009). Gender differences in international students' adjustment. College Student Journal, 43(4), 1217-1227.

Marin, G., Gamba, R., Chun, K., \& Organista, P. (2003). Acculturation and changes in cultural values. In K. Chun, P. Organista, \& G. Marin (Eds.), Acculturation: Advances in theory, measurement, and applied research (83-93). Washington, DC: American Psychological Association.

Marville, A. (1981). The case of international students: A foreign student reports. College Board Review, 120, 23-26.

Maxwell, J. A. (2012). Qualitative research design: An interactive approach. Thousand Oaks, CA: Sage Press.

McLachlan, D. A., \& Justice, J. (2009). A grounded theory of international student well-being. Journal of Theory Construction \& Testing, 13(1), 27-32.

McMillan, J.A., \& Schumacher, S. (2001). Researcher in education: A conceptual introduction. New York, NY: Longman.

Min, P. G. (2001). Changes innder role and social status, and their marital conflicts. Sociological Forum, 16, 301-320.

National Science Board (2014). Science and engineering indicators 2014. Arlington VA: NSF

Newcomb, A., \& Bagwell, C. (1995). Children's friendship relations: A meta analytic review. Psychological Bulletin, 117, 306-347.

Padilla, A., \& Perez, W. (2003). Acculturation, social identity, and social cognition: A new perspective. Hispanic Journal of Behavioral Sciences, 25(1), 35-55. 
Palfreyman, D., \& Smith, R. C. (Eds.). (2003). Learner autonomy across cultures. London: Palgrave Macmillan

Poyrazli, S., \& Kavanaugh, P. R. (2006). Marital status, ethnicity, academic achievement, and adjustment strains. College Student Journal, 40(4), 767-780

Redfield, R., Linton, R., \& Herskovits, M.J. (1936). Memorandum for the study of acculturation. American Anthropologist, 38(1), 149-152

Santisteban, D., Mitrani, V., Chun, K., Organista, P., \& Marin, G. (2003). Ethnic identity and acculturation. In K. Chun, P. Organista, \& G. Marin (Eds.), Acculturation: Advances in theory, measurement, and applied research (121-135). Washington, DC: APA

Sato, T., \& Hodge, S. (2009). Asian international doctoral students' experiences at two American universities: Assimilation, accommodation, and resistance. Journal of Diversity in Higher Education, 2(3), 136-148.

Sherry, M., Thomas, P., \& Wing-Hong, C. (2010). International students: A vulnerable student population. Higher Education, 60(1), 33-46.

Sue, E., \& Rawlings, M. (2013). Preparedness of Chinese students for American culture and communicating in English. Journal of International Students, 3(1), 330-341.

Tang, T. N., \& Dion, K. L. (1999). Gender and acculturation in relation to traditionalism: Perceptions of self and parents among Chinese students. Sex Roles, 41(1), 17-29.

Telbis, N. M., Helgeson, L., \& Kingsbury, C., (2013). International students' confidence and academic success. Journal of International Students, 1(2), 43- 49.

Vedder, P., \& Horenzcyk, G. (2006). Acculturation and the school. In D. L. Sam, \& J. W. Berry (Eds.), Psychology of acculturation: International perspectives (pp. 419-438). Cambridge, UK: Cambridge University Press

Willis, J. (2007). Foundations of qualitative research: Interpretive and critical approaches. Thousand Oaks, CA: Sage Publications.

Ying, Y. W. (2002). The effect of cross-cultural living on personality: Assimilation and accommodation among Taiwanese young adults in the United States. American Journal of Orthopsychiatry, 72(3), 362-371.

Ying, Y. W., \& Han, M. (2006). The contribution of personality, acculturative stressors, and social affiliation to adjustment: A longitudinal study of Taiwanese students in the United States. International Journal of Intercultural Relations, 30(5), 623-635.

Young, A. (2011). First time international college students' level of anxiety in relationship to awareness of their learning-style preferences. J. of International Students, 1(2), 43-49.

Zentella, A. C. (1997). Growing up bilingual: Puerto Rican children in New York. Malden, MA: Blackwell.

Zhang, J., Smith, S., Swisher, M., Fu, D., \& Forgarty, K., (2011). Gender role disruption and marital satisfaction among wives of Chinese international students in the United States. Journal of Comparative Family Studies, 42(3), 523-542.

\section{About Author:}

THROY A. CAMPBELL is a doctoral candidate in K-16 (Educational Leadership and Policy Studies) at the University of Texas at Arlington. He received his master's degree in business administration and finance. His research interests include international students' experiences, education economics and finance, and labor market outcomes of college graduates.

E-mail: Throy.Campbell@mavs.uta.edu 